\title{
Effects of ammonium hexafluorosilicate application on demineralized enamel and dentin of primary teeth
}

\author{
Yumiko Hosoya1), Eiko Watanabe2), Katsumi Tadokoro²), Takashi Inoue3), \\ Masashi Miyazaki ${ }^{4)}$ and Franklin R. Tay5) \\ 1)Department of Pediatric Dentistry, Course of Medical and Dental Science, \\ Nagasaki University Graduate School of Biomedical Sciences, Nagasaki, Japan \\ 2)Oral Health Science Center, Tokyo Dental College, Chiba, Japan \\ 3)Department of Clinical Pathophysiology, Tokyo Dental College, Chiba, Japan \\ 4)Department of Operative Dentistry, Nihon University School of Dentistry, Tokyo, Japan \\ 5)Department of Endodontics, College of Dental Medicine, Georgia Health Sciences University, \\ Augusta, GA, USA
}

(Received 21 May and accepted 11 August 2012)

\begin{abstract}
Silver diamine fluoride $\left(\mathrm{Ag}\left(\mathrm{NH}_{3}\right)_{2} \mathrm{~F}\right)$ arrests caries but stains teeth black. To overcome this drawback, we applied ammonium hexafluorosilicate (AHF; $\left.\left(\mathrm{NH}_{4}\right)_{2} \mathrm{SiF}_{6}\right)$ and observed changes in the color and structure of demineralized enamel and dentin of extracted primary teeth. Enamel and dentin were demineralized in $10 \%$ EDTA solution for $90 \mathrm{~s}$ followed by 35\% phosphoric acid gel for $60 \mathrm{~s}$, then soaked in AHF solution for $60 \mathrm{~s}$. Before analysis by scanning electron microscopy (SEM) and energydispersive X-ray spectrometry (EDS), enamel and dentin were demineralized in $10 \%$ EDTA for $90 \mathrm{~s}$. Teeth were divided into 4 groups according to AHF application and artificial saliva immersion status and then examined. The data were statistically analyzed using one-way ANOVA and Fisher's PLSD test at a significance level of $P<0.05$. AHF treatment did not cause visible discoloration. Enamel prisms and dental tubules appeared by demineralization were covered with precipitates by AHF application. A sphere-filled membranous structure was observed in the saliva
\end{abstract}

Correspondence to Dr. Yumiko Hosoya, Department of Pediatric Dentistry, Course of Medical and Dental Science, Nagasaki University Graduate School of Biomedical Sciences, 1-7-1 Sakamoto, Nagasaki 852-8588, Japan

Tel: +81-95-819-7673

Fax: +81-95-819-7676

E-mail: hosoya@nagasaki-u.ac.jp immersion groups. EDS analysis showed that AHF application had no effect on enamel; however, F\% and $\mathrm{Ca} / \mathrm{P}$ ratio were significantly higher on dentin surfaces after AHF application without artificial saliva immersion. Further study on arresting caries treatment is required. ( $\mathrm{J}$ Oral Sci 54, 267-272, 2012)

Keywords: ammonium hexafluorosilicate; primary teeth; SEM observation; EDS analysis.

\section{Introduction}

Silver diamine fluoride (SDF; $\left.\mathrm{Ag}\left(\mathrm{NH}_{3}\right)_{2} \mathrm{~F}\right)$ has been used to arrest caries since 1969 (1). Arresting caries treatment (ACT) of primary teeth with SDF is useful for managing caries in uncooperative young child patients and in disabled patients. Annual application of 38\% SDF $(44,800 \mathrm{ppm}$ F) to carious primary anterior teeth of Chinese pre-school children was significantly more effective in arresting caries and preventing new caries than three monthly applications of sodium fluoride varnish $(22,600$ ppm F) $(2,3)$. Similarly, bi-annual application of $38 \%$ SDF was clinically effective in arresting caries and preventing new caries in the dentition of school children aged 6 to 15 years over a 3-year period (4).

Although ACT is an acceptable alternative when restorative treatment is not an option $(5,6)$, adverse psychological issues associated with blackening of 


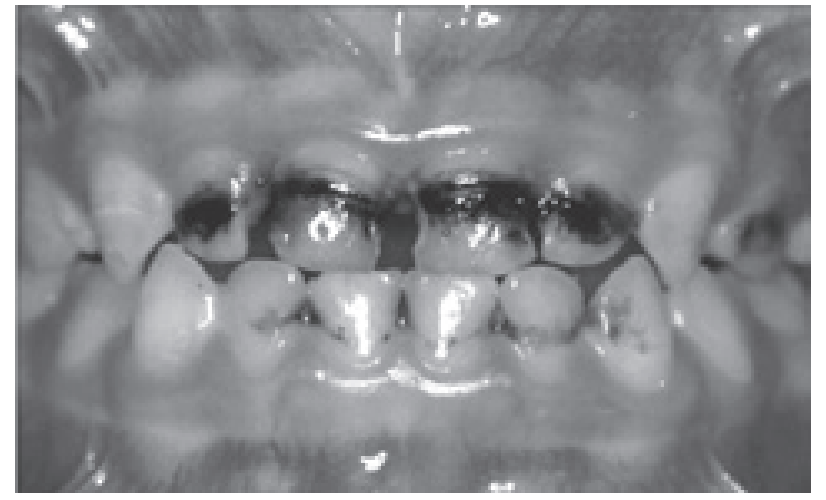

Fig. 1 Photograph of teeth after application of silver diamine fluoride (SDF). Black discoloration was present on caries-infected enamel and dentin, and on remineralized enamel and dentin.

anterior teeth (Fig. 1) have been reported with the use of silver diamine fluoride (7). Suggestions of unsatisfactory prognosis (7) and undesirable effects on the psychology and behavior of patients who had SDF treatment have also been reported $(7,8)$. Treatment of carious dentin with SDF results in the formation of sparingly water-soluble, yellowish silver phosphate that turns black when exposed to sunlight or reducing agents (9).

For prevention of dental caries and treatment of dentin hypersensitivity, ammonium hexafluorosilicate (AHF; $\left.\left(\mathrm{NH}_{4}\right)_{2} \mathrm{SiF}_{6}\right)$ was applied to permanent teeth to overcome tooth discoloration caused by SDF treatment (10). AHF increases the acid resistance of enamel and dentin to almost the same extent as SDF (11). It contains $\mathrm{Si}$, which increases apatite formation (12). Patent dentin tubules within simulated hypersensitive teeth were completely occluded with a silica-calcium phosphate precipitate to a depth of $20 \mu \mathrm{m}$ immediately after AHF treatment, and these tubules induced apatite precipitation on the dentin surface in a simulated oral environment when dentin disks obtained from permanent teeth were immersed in artificial saliva (12). Thus, we hypothesize that AHF treatment may be adequate for arresting caries treatment of primary teeth, without causing tooth discoloration. To our knowledge, there are no data on the effects of AHF treatment on demineralized enamel and dentin of primary teeth. Therefore, in this preliminary study, we observed the effects of AHF treatment on elemental changes in demineralized enamel and dentin of primary teeth.

The objective of the present study was to examine changes in the structure of artificially demineralized enamel and dentin of sound primary teeth after AHF treatment. The null hypothesis tested was that AHF application does not influence the elemental content of demineralized enamel and dentin.

\section{Materials and Methods \\ Experimental teeth}

Healthy primary canines and primary molars that were extracted either to expedite eruption of the succedaneous tooth or for orthodontic reasons were used. Informed consent for tooth collection was obtained from parents and patients, according to the regulations of Nagasaki University Dental School (Permission No. 26). The teeth were frozen in physiologic saline within 10 min after extraction.

\section{AHF solution and artificial saliva}

AHF (Kanto Chemical Co. Inc., Tokyo, Japan) was used without further purification and was dissolved in double-distilled water to produce a $0.476 \mathrm{~mol} / \mathrm{L}$ solution (pH 3.4). Artificial saliva, which has an electrolyte composition similar to that of human saliva, was prepared from $1.09 \mathrm{mmol} / \mathrm{L} \mathrm{CaCl}, 0.68 \mathrm{mmol} / \mathrm{L} \mathrm{KH}_{2} \mathrm{PO}_{4}, 30$ $\mathrm{mmol} / \mathrm{L} \mathrm{KCl}$, and $2.6 \mathrm{mmol} / \mathrm{L} \mathrm{NaF}$. The artificial saliva was buffered to $\mathrm{pH} 7.0$ with $50 \mathrm{mmol} / \mathrm{L}$ HEPES ( $N$-2-hydroxyethylpiperazine- $N$ '-2' ethane sulfonic acid).

\section{Scanning electron microscopy (SEM) and energy-dispersive X-ray spectrometry (EDS) analysis}

Twelve primary teeth (six primary canines and six primary molars) were used. To produce flat dentin surfaces surrounded by enamel, the labial and lingual surfaces of primary canines, and the buccal, lingual, and occlusal surfaces of primary molars, were ground with a diamond bur and polished with 600-grit silicon carbide paper under copious water cooling. Dentin pulps were removed, and the pulp chambers of the teeth were filled with white wax (Shofu Co., Kyoto, Japan). The teeth were demineralized in 10\% EDTA ( $\mathrm{pH} 7.2$ ) for $90 \mathrm{~s}$ and ultrasonically cleaned in distilled water. Each tooth was additionally etched with $35 \%$ phosphoric acid gel (Kuraray Medical Co., Tokyo, Japan) for $60 \mathrm{~s}$ and ultrasonically cleaned in distilled water. The teeth were divided into four groups, based on the method of treatment with AHF and/or artificial saliva: Group A (neither AHF application nor artificial saliva immersion-control), Group B (immersion in artificial saliva only), Group C (AHF application only), and Group D (AHF application and artificial saliva immersion). In the AHF application groups (Groups C and D), AHF solution was rubbed on the demineralized enamel and dentin surfaces with a cotton swab for $3 \mathrm{~min}$. In the artificial saliva groups (Groups B and D), each tooth was soaked in a glass bottle filled with $10 \mathrm{~mL}$ of artificial saliva at $37^{\circ} \mathrm{C}$ for 7 days. The artificial saliva was changed every 
Table 1 Mean (SD) values for elemental content of enamel in the 4 groups (mass \%)

\begin{tabular}{|c|c|c|c|c|c|c|c|c|c|c|c|}
\hline Group & AHF & $\begin{array}{c}\text { Artifi- } \\
\text { cial } \\
\text { saliva }\end{array}$ & $\begin{array}{l}\text { Mea- } \\
\text { suring } \\
\text { point }\end{array}$ & $\begin{array}{c}\text { Dis- } \\
\text { tance } \\
\text { from } \\
\text { surface } \\
(\mu \mathrm{m})\end{array}$ & $\mathrm{F}$ & $\mathrm{P}$ & $\mathrm{Ca}$ & $\mathrm{O}$ & $\mathrm{Si}$ & $\mathrm{Mg}$ & $\mathrm{Ca} / \mathrm{P}$ \\
\hline \multirow[t]{4}{*}{ A } & - & - & 1 & 0 & $0.00(0.00) \mathrm{a}, 1$ & $12.6(3.3) b, 1$ & 24.7 ( 9.5) a, 2 & $62.3(12.6)$ a, 2 & $0.23(0.18)$ a, 1,2 & $0.18(0.03)$ a, 2 & $1.92(0.24)$ a, 1 \\
\hline & & & 2 & 5 & $0.03(0.00)$ a, 1 & $17.2(0.1)$ a, 1,2 & 36.2 ( 2.4) a, 1, 2 & $46.4(2.5) \mathrm{a}, 1,2$ & $0.04(0.00) \mathrm{a}, 1$ & $0.20(0.03)$ a, 2 & $2.11(0.13)$ a, 1 \\
\hline & & & 3 & 10 & $0.00(0.00)$ a, 1 & $17.3(0.7)$ a, 1,2 & 36.1 ( 1.7) a, 1,2 & $46.2(2.3)$ a, 1,2 & $0.14(0.01)$ a, 1 & $0.18(0.02)$ a, 2 & $2.08(0.01) \mathrm{a}, 1$ \\
\hline & & & 4 & 15 & $0.02(0.00)$ a, 1 & $18.3(0.3)$ a, 1 & $37.0(1.3)$ a, 1,2 & $44.5(1.5)$ a, 1,2 & $0.12(0.06)$ a, 1 & $0.19(0.03)$ a, 2 & $2.03(0.04) \mathrm{a}, 1$ \\
\hline \multirow[t]{4}{*}{ B } & - & + & 1 & 0 & $0.37(0.24)$ a, 1 & $12.6(0.6)$ a, 1 & 25.7 ( 1.9) a, 2 & $61.0(2.4) \mathrm{a}, 2$ & $0.11(0.06)$ a, 2 & $0.22(0.08)$ a, 2 & $2.03(0.07) \mathrm{a}, 1$ \\
\hline & & & 2 & 5 & $0.31(0.28)$ a, 1 & $14.1(1.2)$ a, 1 & $29.0(3.5)$ a, 2 & $56.2(4.5)$ a, 2 & $0.12(0.06)$ a, 1 & $0.23(0.04)$ a, 2 & $2.05(0.07)$ a, 1 \\
\hline & & & 3 & 10 & $0.39(0.24)$ a, 1 & $15.4(0.7)$ a, 1 & 31.7 ( 2.7) a, 2 & $52.4(3.1)$ a, 2 & $0.09(0.06)$ a, 1 & $0.26(0.08)$ a, 2 & $2.06(0.09)$ a, 1 \\
\hline & & & 4 & 15 & $0.16(0.15)$ a, 1 & $15.5(0.6)$ a, 1 & 32.7 ( 2.1) a, 2 & $51.4(2.4)$ a, 2 & $0.08(0.05)$ a, 1 & $0.26(0.11) \mathrm{a}, 2$ & $2.11(0.07)$ a, 1 \\
\hline \multirow[t]{4}{*}{$\mathrm{C}$} & + & - & 1 & 0 & $0.82(0.91)$ a, 1 & $14.8(2.9) \mathrm{b}, 1$ & $45.4(17.2) \mathrm{a}, 1$ & $37.7(17.2) \mathrm{a}, 1$ & $0.62(0.59) \mathrm{a}, 1$ & $0.68(0.37)$ a, 1 & $3.30(1.89)$ a, 2 \\
\hline & & & 2 & 5 & $0.80(1.28)$ a, 1 & $18.4(3.8)$ a, 2 & $46.2(10.7) \mathrm{a}, 1$ & 33.5 (12.9) a, 1 & $0.45(0.43) \mathrm{a}, 1$ & $0.67(0.36) \mathrm{a}, 1$ & $2.69(1.32) \mathrm{a}, 1$ \\
\hline & & & 3 & 10 & $1.50(2.46) \mathrm{a}, 1$ & $18.3(3.9)$ a, 2 & 48.8 (12.7) a, 1 & 30.5 (15.1) a, 1 & $0.37(0.33)$ a, 1 & $0.67(0.37) \mathrm{a}, 1$ & $2.86(1.36) \mathrm{a}, 1$ \\
\hline & & & 4 & 15 & $0.88(1.76)$ a, 1 & $18.1(2.1)$ a, 1 & 44.5 ( 9.0) a, 1 & 35.4 (10.6) a, 1 & $0.43(0.41)$ a, 1 & $0.73(0.33)$ a, 1 & $2.49(0.67)$ a, 1 \\
\hline \multirow[t]{4}{*}{ D } & + & + & 1 & 0 & $0.87(0.55)$ a, 1 & $14.9(2.3) \mathrm{c}, 1$ & $30.4(5.5) b, 2$ & $53.6(8.2)$ a, 2 & $0.24(0.15)$ a, 1,2 & $0.11(0.07) \mathrm{a}, 2$ & $2.05(2.39) \mathrm{b}, 1$ \\
\hline & & & 2 & 5 & $0.49(0.48)$ a, 1 & $18.2(2.6) b, c, 2$ & $45.2(11.1) \mathrm{a}, 1$ & $35.8(13.2) \mathrm{b}, \mathrm{c}, 1$ & $0.09(0.06) \mathrm{a}, 1$ & $0.17(0.06) \mathrm{a}, 2$ & $2.45(0.30) \mathrm{a}, 1$ \\
\hline & & & 3 & 10 & $0.56(0.85)$ a, 1 & 20.5 (4.2) a, b, 2 & $50.4(14.0)$ a, 1 & $28.3(17.6) \mathrm{c}, 1$ & $0.15(0.08)$ a, 1 & $0.18(0.06)$ a, 2 & $2.43(0.22) \mathrm{a}, 1$ \\
\hline & & & 4 & 15 & $0.03(0.03) \mathrm{a}, 1$ & $17.6(0.3) b, c, 1$ & $37.8(1.5) \mathrm{a}, \mathrm{b}, 1$ & $44.3(1.4) a, b, 1,2$ & $0.06(0.08) \mathrm{a}, 1$ & $0.23(0.04)$ a, 2 & $2.16(0.10) \mathrm{a}, 1$ \\
\hline
\end{tabular}

AHF, ammonium hexafluorosilicate

Between the values with identical letters $(a, b)$ in each groups indicate no significant difference $(P>0.05)$.

Between the values with identical numerals $(1,2)$ in same measuring points indicate no significant difference $(P>0.05)$.

$24 \mathrm{~h}$, and AHF was applied every $48 \mathrm{~h}$. In Group C, AHF solution was applied, and the teeth were kept in $100 \%$ relative humidity for 7 days.

After AHF application and/or artificial saliva immersion, the teeth were fixed in $0.1 \mathrm{~mol} / \mathrm{L}$ cacodylic acid-buffered solution containing $2.5 \%$ glutaraldehyde and $2 \%$ paraformaldehyde for $1 \mathrm{~h}$ and dried in a desiccator. Specimens were buccolingually sectioned at the center of the tooth using a low-speed diamond saw (Isomet, Buehler, Lake Bluff, IL, USA) and mirror-polished. One side of the sectioned tooth was used for SEM/EDS analysis, and the other side was used for SEM observation. The surfaces were carbon-coated for SEM/EDS analysis (Electron Probe Microanalyzer JXA-8200, JEOL, Tokyo, Japan) and Au/Pd-coated for SEM observation (JSM6340F, JEOL).

For SEM/EDS analysis, the elemental content of enamel and dentin was analyzed at $20 \mathrm{kV}$ and 2000× magnification in 5- $\mu \mathrm{m}$ intervals, perpendicular from the AHF-applied surface to the pulp chamber. Three to five measuring lines were set for each of the test surfaces. Analysis was performed with ZAF correction (atomic number, absorption, and fluorescence) based on standardless correction.

The data were analyzed using one-way analysis of variance to determine the effects of analysis location (distance away from AHF-applied surface) and the effects among groups (with or without AHF application and artificial saliva immersion) on elemental distributions. Post-hoc comparisons were performed using Fisher's PLSD test. Statistical significance for all tests was pre-set at $\alpha=0.05$.

\section{Results}

The results of SEM/EDS analysis are shown in Tables 1 and 2. Table 1 shows the elemental content in enamel for each group. Regarding the mass \% of each element at the different measuring points in each group, $\mathrm{P}$ (phosphorus)\% at measuring point 1 in groups without artificial saliva immersion (Groups A and C) was significantly lower than at the other measuring points. In addition, the $\mathrm{Ca} / \mathrm{P}$ ratio at point 1 in Group $\mathrm{D}$ was significantly lower than at the other measuring points. Regarding the elements at point 1 among groups, $\mathrm{Ca}$ (calcium) $\%, \mathrm{Mg}$ (magnesium)\%, and $\mathrm{Ca} / \mathrm{P}$ ratio were significantly higher in Group $\mathrm{C}$ than in the other groups.

Table 2 shows the elemental content of dentin for each group. Regarding F (fluoride)\%, only Group C showed a significant difference among measuring points: $\mathrm{F} \%$ at measuring point 1 was significantly higher than at points 3 and $4 . \mathrm{Ca} \%$ at point 1 was significantly lower than at points 2, 3, and 4 in Group A. In Group D, Ca\% at point 1 was significantly lower than at points 3 and 4 . In Group $\mathrm{C}, \mathrm{Mg} \%$ at points 1 and 2 was significantly higher than 
Table 2 Mean (SD) values for elemental content of dentin in the 4 groups (mass \%)

\begin{tabular}{|c|c|c|c|c|c|c|c|c|c|c|c|}
\hline Group & AHF & $\begin{array}{c}\text { Artifi- } \\
\text { cial } \\
\text { saliva }\end{array}$ & $\begin{array}{c}\text { Mea- } \\
\text { suring } \\
\text { point }\end{array}$ & $\begin{array}{c}\text { Dis- } \\
\text { tance } \\
\text { from } \\
\text { surface } \\
(\mu \mathrm{m})\end{array}$ & $\mathrm{F}$ & $P$ & $\mathrm{Ca}$ & $\mathrm{O}$ & $\mathrm{Si}$ & $\mathrm{Mg}$ & $\mathrm{Ca} / \mathrm{P}$ \\
\hline \multirow[t]{4}{*}{ A } & - & - & 1 & 0 & $0.04(0.02)$ a, 2 & $12.9(2.2)$ a, 1 & $25.5(5.4) b, 2$ & $60.9(7.7) \mathrm{a}, 2$ & $0.16(0.06) \mathrm{a}, 2$ & $0.60(0.14)$ a, 2 & $2.00(0.11)$ a, 3 \\
\hline & & & 2 & 5 & $0.05(0.03)$ a, 2 & $15.7(2.2)$ a, 1 & 33.0 ( 6.8$)$ a, 2 & $50.6(8.9)$ a, b, 2 & $0.06(0.04)$ a, 2 & $0.60(0.07)$ a, 2 & $2.08(0.18)$ a, 2 \\
\hline & & & 3 & 10 & $0.08(0.04)$ a, 1 & $17.1(2.2) \mathrm{a}, 1,2$ & 44.0 (13.8) a, 2 & $43.8(10.8) b, 1,2$ & $0.11(0.06) \mathrm{a}, 1$ & $0.58(0.19) \mathrm{a}, 2$ & $2.22(0.27) \mathrm{a}, 1$ \\
\hline & & & 4 & 15 & $0.10(0.08)$ a, 1 & $18.0(1.4)$ a, 1 & 41.1 ( 6.6) a, 1, 2 & $40.2(7.6) b, 1,2$ & $0.14(0.04) \mathrm{a}, 1$ & $0.51(0.09)$ a, 2 & $2.27(0.27) \mathrm{a}, 1$ \\
\hline \multirow[t]{4}{*}{ B } & - & + & 1 & 0 & $0.14(0.13)$ a, 2 & $13.2(2.1)$ a, 1 & 26.7 ( 4.9) a, 2 & $59.2(7.0)$ a, 2 & $0.15(0.07)$ a, 2 & $0.63(0.21)$ a, 2 & $2.02(0.08)$ a, 3 \\
\hline & & & 2 & 5 & $0.20(0.19)$ a, 2 & $14.6(1.9)$ a, 1 & $30.0(4.8)$ a, 2 & 54.3 ( 6.7) a, 2 & $0.12(0.04) \mathrm{a}, 2$ & $0.73(0.21)$ a, 2 & $2.05(0.08)$ a, 2 \\
\hline & & & 3 & 10 & $0.13(0.12)$ a, 1 & $15.3(1.8)$ a, 2 & 31.9 ( 5.0) a, 2 & 51.8 ( 6.8) a, 2 & $0.10(0.03) \mathrm{a}, 1$ & $0.70(0.13)$ a, 1,2 & $2.07(0.10) \mathrm{a}, 1$ \\
\hline & & & 4 & 15 & $0.11(0.09)$ a, 1 & $15.6(1.0)$ a, 1 & 33.3 ( 5.8) a, 2 & 50.2 ( 6.6) a, 2 & $0.08(0.06)$ a, 1 & $0.72(0.14)$ a, 1,2 & $2.13(0.24)$ a, 1 \\
\hline \multirow[t]{4}{*}{$\mathrm{C}$} & + & - & 1 & 0 & $2.16(2.31)$ a, 1 & $11.6(4.2) b, 1$ & $42.0(14.3)$ a, 1 & 40.4 (13.8) a, 1 & $1.36(1.13) \mathrm{a}, 1$ & $1.20(0.25)$ a, 1 & $4.57(2.98) \mathrm{a}, 1$ \\
\hline & & & 2 & 5 & $1.47(1.66)$ a, b, 1 & $16.6(3.7) b, 1$ & $46.4(10.5)$ a, 1 & 33.9 (11.3) a, 1 & $0.77(1.22) \mathrm{a}, 1$ & $1.10(0.26) \mathrm{a}, 1$ & $2.99(1.25) b, 1,2$ \\
\hline & & & 3 & 10 & $0.86(1.19) \quad b, 1$ & $25.0(5.6) \mathrm{a}, 1$ & 43.1 ( 8.4) a, 1 & 36.4 (10.7) a, 1 & $0.51(0.92) \mathrm{a}, 1$ & $0.90(0.27) b, 1$ & $2.45(0.54) b, 1$ \\
\hline & & & 4 & 15 & $0.77(0.98) \quad b, 1$ & $18.4(2.2) \mathrm{a}, \mathrm{b}, 1$ & 43.1 ( 9.2) a, 1 & 36.4 (11.3) a, 1 & $0.48(0.78)$ a, 1 & $0.90(0.35) b, 1$ & $2.35(0.49) \mathrm{b}, 1$ \\
\hline \multirow[t]{4}{*}{ D } & + & + & 1 & 0 & $0.60(0.91)$ a, 2 & $11.2(5.5)$ a, 1 & 28.6 ( 9.9) b, 2 & $62.3(16.2)$ a, 2 & $0.91(0.05)$ a, 2 & $0.42(0.23) b, 2$ & $3.37(1.51)$ a, 2 \\
\hline & & & 2 & 5 & $0.08(0.09)$ a, 2 & $13.0(5.3)$ a, 1 & $35.7(7.7) b, 2$ & $50.6(12.1) \mathrm{b}, 2$ & $0.19(0.27) \mathrm{a}, 1$ & $0.62(0.28) a, 2$ & 3.34 (1.86) a, 1 \\
\hline & & & 3 & 10 & $0.01(0.002) \mathrm{a}, 1$ & $17.0(3.5) \mathrm{a}, 2$ & $44.0(13.8)$ a, 1 & $39.8(18.5) \mathrm{c}, 1$ & $0.10(0.08)$ a, 1 & $0.60(0.31) a, b, 2$ & $2.72(0.53)$ a, 1 \\
\hline & & & 4 & 15 & $0.06(0.07) \mathrm{a}, 1$ & $15.9(5.4)$ a, 1 & 43.8 (14.7) a, 1 & $39.7(19.2) \mathrm{c}, 1,2$ & $0.12(0.07) \mathrm{a}, 1$ & $0.62(0.32) \mathrm{a}, 2$ & $2.91(0.76) \mathrm{a}, 1$ \\
\hline
\end{tabular}

AHF, ammonium hexafluorosilicate

Between the values with identical letters $(a, b)$ in each groups indicate no significant difference $(P>0.05)$.

Between the values with identical numerals $(1,2)$ in same measuring points indicate no significant difference $(P>0.05)$.

at points 3 and 4 , and $\mathrm{Ca} / \mathrm{P}$ ratio at point 1 was significantly higher than at the other points. In a comparison of elements among different groups at point $1, \mathrm{~F} \%, \mathrm{Ca} \%$, $\mathrm{Si} \%, \mathrm{Mg} \%$, and $\mathrm{Ca} / \mathrm{P}$ ratio were significantly higher in Group $\mathrm{C}$ than in the other groups. The $\mathrm{Ca} / \mathrm{P}$ ratio at point 1 was highest in Group C, followed by Groups D, B, and $\mathrm{A}$, in that order. All differences between groups were significant, except for the comparison between Groups $\mathrm{B}$ and $\mathrm{A}$.

SEM images are shown in Fig. 2. After EDTA treatment and phosphoric acid etching in Group A, etched enamel surface (Fig. A-E) and patent dentinal tubules (Fig. A-D) were observed. After immersion in artificial saliva (Group B), amorphous materials on enamel (Fig. B-E) and a membranous structure on dentin (Fig. B-D) were observed. Regardless of whether teeth were immersed in artificial saliva, enamel surfaces treated with AHF (Groups C and D) were covered with spherical particles, which formed a continuous gel-like membrane (Figs. C-E and D-E). Regarding AHF-treated dentin in Group C, many dentinal tubules that were rendered patent by EDTA demineralization were filled with the spherical particles (Fig. C-D). In Group D, the entire enamel and dentin surfaces were covered with a membranous structure comprising spherical particles (Figs. D-E, D-D, and D-FD).

\section{Discussion}

A previous study showed that although the color of human molar dentin that had been treated with SDF for 3 min changed to black due to silver precipitation, a 3 -min AHF treatment did not change the color of dentin (13). No previous report has objectively compared the color of enamel and dentin treated with AHF and SDF in permanent or primary teeth.

The elemental content of enamel (Table 1) was not significantly changed by AHF application on enamel. Regarding dentin (Table 2), in Group C (AHF application without artificial saliva immersion), $\mathrm{F} \%$ on the dentin surface (point 1) was significantly higher than at $10-15 \mu \mathrm{m}$ beneath the surface (points 3 and 4), and the $\mathrm{Ca} / \mathrm{P}$ ratio on the dentin surface was significantly higher than at 5-15 $\mu \mathrm{m}$ beneath the surface (points 2, 3, and 4). However, in Group D (AHF application with artificial saliva immersion), there was no significant difference in the values for these elements at different measuring points. At measuring point 1 (dentin surface), $\mathrm{F} \%, \mathrm{Ca} \%, \mathrm{Si} \%, \mathrm{Mg} \%$, and $\mathrm{Ca} / \mathrm{P}$ ratio were significantly higher in Group $\mathrm{C}$ than in the other groups. Thus it is possible that AHF was dissolved by artificial saliva, thereby nullifying its anti-caries effect. Because the AHF solution used in the present study was acidic ( $\mathrm{pH} 3.4)$, repeated AHF application is not recommended. If our in vitro inference is correct, the efficacy of AHF treatment 

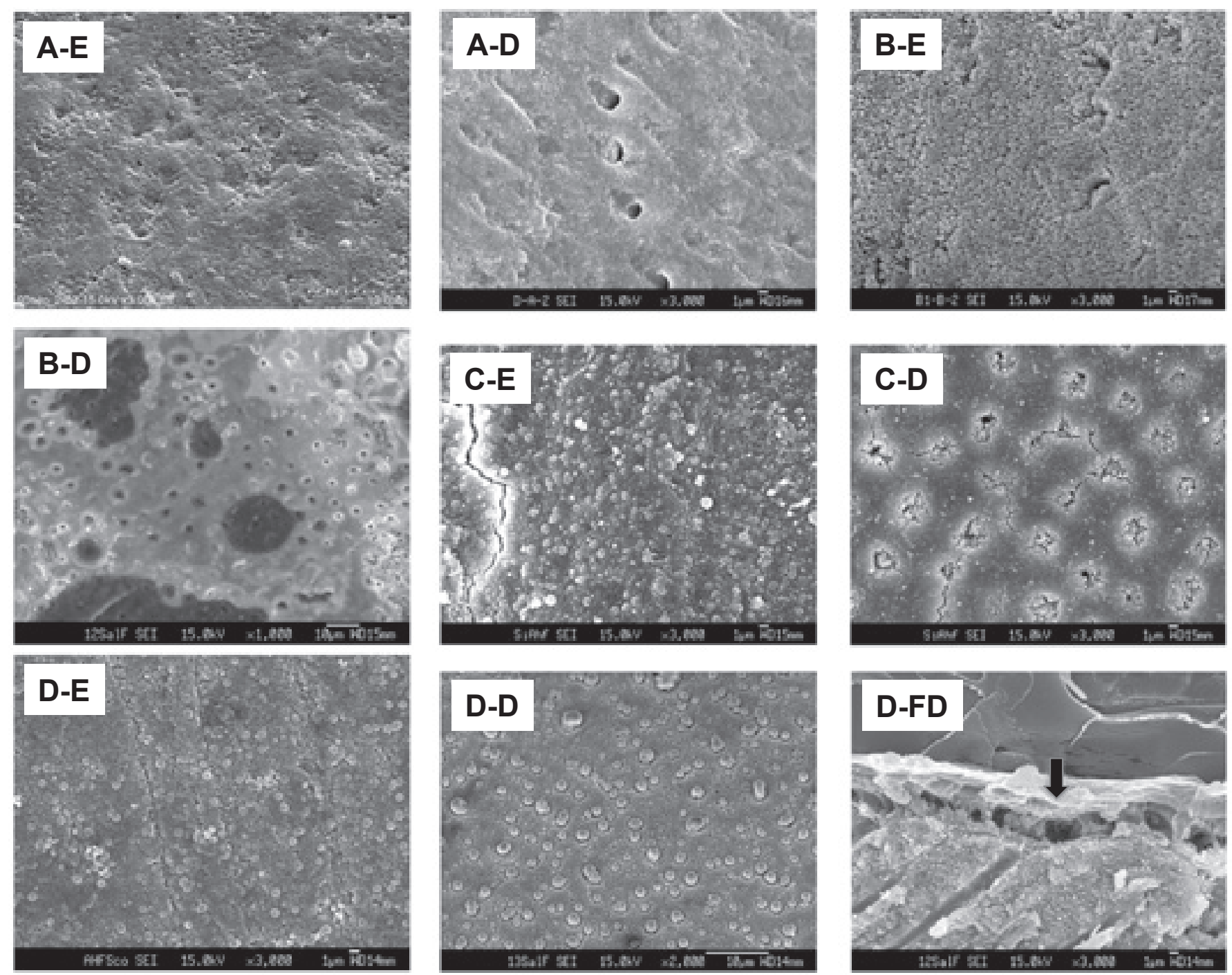

Fig. 2 Scanning electron microscopic images of demineralized enamel and dentin. A-E: Enamel of Group A (neither AHF application nor artificial saliva immersion-control). The enamel surface was rough. A-D: Dentin of Group A. Some patent dentinal tubules were observed. B-E: Enamel of Group B (artificial saliva immersion only). Enamel was covered with amorphous material. B-D: Dentin of Group B. Dentin surface was covered with a membranous structure, however, patent dentinal tubules were observed. C-E: Enamel of Group C (AHF application only). Enamel was covered with spherical particles (approximately $1 \mu \mathrm{m}$ in diameter). C-D: Dentin of Group C. Dentinal tubules were occluded with spherical particles. D-E: Enamel of Group D (AHF application followed by artificial saliva immersion). Enamel surface was covered with spherical particles approximately $1 \mu \mathrm{m}$ in diameter. D-D: Dentin of Group D. Dentin surface was covered with spherical particles approximately $1 \mu \mathrm{m}$ in diameter. Patent dentinal tubules were not observed. D-DF: Fractured dentin in Group D. The dentin surface was covered with a membranous structure (arrow) consisting of spherical particle aggregates.

may be lower in an oral environment. In this study, the level of demineralization, both for enamel and dentin, might differ among teeth and tested surfaces (Tables 1 and 2). In future studies, the method used to demineralize enamel and dentin of primary teeth should be examined, and identical surfaces should be used for EDS analysis. As shown in Table 2, the $\mathrm{Ca} / \mathrm{P}$ ratio was high in all the groups, especially at points 1 and 2 in dentin of Group $\mathrm{C}$ and Group D samples; standard deviations were also high. The high $\mathrm{Ca} / \mathrm{P}$ ratio may be due to silica-calcium phosphate precipitation by AHF (14); a reaction with the artificial saliva occurred not only on the enamel and dentin surfaces but also in dentinal tubules (Fig. 2; D-E, D-D).

Previous studies $(13,14)$ reported that precipitates deposited in the dentinal tubules after AHF treatment contained $\mathrm{F}, \mathrm{Ca}$, and $\mathrm{P}$ and appeared to be composed of a mixture of fluoridated apatite and calcium fluoride-like minerals. Calcium fluoride and calcium fluoride-like minerals act as fluoride reservoirs in the oral environment. 
As compared with fluorapatite, calcium fluoride deposits are more susceptible to being washed away or dissolved $(15,16)$. Fluorapatite is stable and does not dissolve in saliva because it is supersaturated in comparison with saliva. Thus, continuous dentin tubule occlusion can be achieved with the deposition of fluorapatite (16). In addition, silica-containing compounds induce apatite formation from simulated body fluids and artificial saliva (12). If the silica content of dentinal tubular precipitates is increased, further mineralization of the dentin surface can be expected, resulting in more-prolonged tubule occlusion (16). As compared with dentin, the enamel structure has disadvantageous to reserve calcium fluoride and calcium fluoride-like minerals (Fig. 2; A-E, A-D). That is one of the main reasons why AHF is less effective on enamel than on dentin.

Within the limits of the present study, the null hypothesis that AHF application does not influence the elemental content of demineralized enamel and dentin must be partially rejected. Although AHF application had no clear effect on enamel, both $\mathrm{F} \%$ and $\mathrm{Ca} / \mathrm{P}$ ratio were significantly higher on the dentin surface after AHF application without artificial saliva immersion. Future studies should evaluate stability in the oral environment of precipitate formed by AHF treatment and the efficacy on arresting caries treatment.

\section{Acknowledgments}

This work was supported, in part, by a Grant-in-Aid for Scientific Research C (No. 21592601) from the Japanese Society for the Promotion of Science (JSPS).

\section{References}

1. Nishino M, Yoshida S (1969) Clinical effects of diamine silver fluoride on caries and on pulp of deciduous teeth. Shoni Shikagaku Zasshi 7, 55-59. (in Japanese)

2. Lo EC, Chu CH, Lin HC (2001) A communitybased caries control program for pre-school children using topical fluorides: 18-month results. J Dent Res 80, 2071-2074.

3. Chu CH, Lo EC, Lin HC (2002) Effectiveness of silver diamine fluoride and sodium fluoride varnish in arresting dentin caries in Chinese pre-school children. J Dent Res 81, 767-770.

4. Llodra JC, Rodriguez A, Ferrer B, Menardia V, Ramos T, Morato M (2005) Efficacy of silver diamine fluoride for caries reduction in primary teeth and first permanent molars of schoolchildren: 36-month clinical trial. J Dent Res 84, 721-724.

5. Rosenblatt A, Stamford TCM, Niederman R (2009)
Silver diamine fluoride: a caries "silver-fluoride bullet”. J Dent Res 88, 116-125.

6. Yee R, Holmgren C, Mulder J, Lama D, Walker D, van Palenstein Helderman W (2009) Efficacy of silver diamine fluoride for arresting caries treatment. J Dent Res 88, 644-647.

7. Kasahara H, Omura Y, Matsuda A, Nakano J, Tonomura M, Imanishi T (1984) Survey of consciousness of anterior teeth in children - significance of esthetic repair of anterior deciduous teeth. Shoni Shikagaku Zasshi 22, 365-372. (in Japanese)

8. Nagayama M, Mishima A (1981) Self-injured periodontal case in primary dentition - concerning Saforide $^{\circledR}$. Hokkaido Shikaishi Kaishi 35, 99-103. (in Japanese)

9. Yamaga R, Nishino M, Yoshida S, Yokomizo I (1972) Diammine silver fluoride and its clinical application. J Osaka Univ Dent Sch 12, 1-20.

10. Murata H, Ishikawa $\mathrm{K}$, Tenshin $\mathrm{S}$, Horiuchi $\mathrm{S}$, Nakanishi M, Asaoka K, Kawata T, Yamamoto TT (1996) Fluoridation of hydroxyapatite powder by ammonium hexafluorosilicate. Caries Res 30, 465-470.

11. Kawasaki A, Suge T, Ishikawa K, Ozaki K, Matsuo T, Ebisu S (2005) Ammonium hexafluorossilicate increased acid resistance of bovine enamel and dentine. J Mater Sci Mater Med 16, 461-466.

12. Li P, Nakanishi K, Kokubo T, de Groot K (1993) Induction and morphology of hydroxyapatite, precipitated from metastable simulated body fluids on sol-gel prepared silica. Biomaterials 14, 963-968.

13. Suge T, Kawasaki A, Ishikawa K, Matsuo T, Ebisu S (2006) Effect of ammonium hexafluorosilicate on dentin tubule occlusion for the treatment of dentin hypersensitivity. Am J Dent 19, 248-252.

14. Suge T, Kawasaki A, Ishikawa K, Matsuo T, Ebisu S (2010) Effects of ammonium hexafluorosilicate concentration on dentin tubule occlusion and composition of the precipitate. Dent Mater 26, 29-34.

15. Sieck B, Takagi S, Chow LC (1990) Assessment of loosely-bound and firmly-bound fluoride uptake by tooth enamel from topically applied fluoride treatments. J Dent Res 69, 1261-1265.

16. Takagi S, Chow LC, Sieck BA (1992) Deposition of loosely bound and firmly bound fluorides on tooth enamel by an acidic gel containing fluorosilicate and monocalcium phosphate monohydrate. Caries Res 26, 321-327. 